\title{
O pensamento de Gramsci e o Estado brasileiro: contribuições ao Serviço Social
}

\author{
Salyanna de Souza Silva'
}

\section{Resumo}

É inegável a importância das contribuições do marxista italiano Antonio Gramsci para o estudo do Estado moderno, teoria essa que influência até hoje o Serviço Social brasileiro. O presente trabalho busca fazer uma análise sobre desenvolvimento do Estado brasileiro até os dias atuais a partir das contribuições teóricas do marxista italiano Antonio Gramsci. Trata-se de um estudo que a partir de uma revisão de literatura, analisa algumas categorias gramscianas, trazendo-as para a realidade nacional, se utilizando também de autores como Carlos Nelson Coutinho (1993) e Florestan Fernandes (2006). Dividido em dois pontos, inicialmente discorremos sobre o conceito Estado em Gramsci e posteriormente buscamos analisar elementos da realidade nacional. Nossa trajetória aponta para uma sociedade que foi a duras penas caminhando para uma "ocidentalização", malgrado os ataques violentos e conservadores de uma burguesia que não foi capaz de realizar uma reforma democrática.

\section{Palavras-chave}

Teoria do Estado em Gramsci; Estado brasileiro; Formação Social brasileira; Fundamentos do Serviço Social.

\section{Gramsci's thought and the Brazilian State: contributions to Social Work}

\begin{abstract}
It is undeniable the importance of the contributions of the Italian Marxist Antonio Gramsci to the study of the modern State, a theory that still influences the Brazilian Social Service. The present work seeks to make an analysis on the development of the Brazilian State until the present day from the theoretical contributions of the Italian Marxist Antonio Gramsci. It is a study that, based on a literature review, analyzes some Gramscian categories, bringing them to the national reality, also using authors such as Carlos Nelson Coutinho (1993) and Florestan Fernandes (2006). Divided into two points, we initially discussed the concept of State in Gramsci and later we sought to analyze elements of the national reality. Our trajectory points to a society that was struggling towards "westernization", in spite of the violent and conservative attacks of a bourgeoisie that was not able to carry out a democratic reform.
\end{abstract}

\section{Keywords}

Theory of the State in Gramsci; Brazilian state; Brazilian Social Formation; Fundamentals of Social Work.

Artigo recebido: março de 2021

Artigo aprovado: maio de 2021 


\section{Introdução}

O alcance dos estudos do marxista italiano Antonio Gramsci (18911937) no Serviço Social brasileiro acompanha a influência do próprio marxismo na profissão, bem como na esquerda nacional. Nesse sentido, embora as obras gramscianas na América Latina remontem os anos de 1950, com a publicação das Cartas do cárcere pela Ediciones Lautaro em Buenos Aires, sua inserção no Brasil foi atravessada por dois importantes obstáculos, a saber: a censura promovida pela Ditadura civil-militar (1964-1985) com a subsequente decretação do Al-5 (1968) e a então cultura dominante da esquerda nacional que era influenciada pelo "marxismo da Terceira Internacional" ou "marxismo-leninismo", que além de se expressar como concepção de marxismo, reverbera na própria leitura de realidade brasileira² (SIMIONATTO, 2011).

De uma forma geral, Simionatto (2011) evidencia que a recepção das ideias do marxista italiano no Brasil se deu em dois importantes ciclos, no primeiro alinham-se as publicações da década de 1960, que compreendem os trabalhos de Carlos Nelson Coutinho, Leandro Konder, Michael Löwy e Otto Maria Carpeaux.

Sobre esse período vale ressaltar a primeira publicação dos Cadernos do cárcere no Brasil, que data de 1966, tradução de Luiz Mário Gazzaneo, Carlos Nelson Coutinho e Leandro Konder. Tal edição seguiu a experiência inicial italiana, sendo uma edição temática, que segundo Bianchi (2018, p. 41) além de apresentar traduções equivocadas e ainda excluiu os prefácios da edição italiana, o que deixou "o leitor brasileiro sem saber que se tratava de uma reconstrução do texto original".

Enquanto no segundo ciclo encontram-se as produções da metade das décadas de 1970 e 1980, período auge da produção teórica sobre o autor, tal ciclo ganha fôlego acompanhando a crise da autocracia, marcada em 1979 pela revogação do Al-5, com subsequente reabertura política e cultural no Brasil.

Somente no final dos anos 1990, os Cadernos ganham uma nova edição pela Civilização Brasileira com Carlos Nelson Coutinho. Com 
um total de 06 volumes, tal edição trata-se de um mix entre aquela temática e respeitando ainda a estrutura dos cadernos.

Imerso a essa realidade é que o marxismo e o pensamento de Antonio Gramsci incidem no Serviço Social brasileiro, a partir de contribuições na análise sobre o Estado, hegemonia, o papel dos intelectuais, etc. Como marco importante para profissão destacamos o Movimento de Reconceituação ${ }^{3}$, que mobilizou a categoria em toda a América Latina.

Segundo Guido Liguori (2012) a obra de Cramsci pode ser considerada "complexa, labiríntica e aberta", existindo diversas interpretações e polêmicas até hoje. Em linhas gerais, o referido autor destaca duas diferentes leituras: uma primeira relacionada à visão "comunista", "togliattiana, antitogliattiana ou post-togliattiana", na qual Cramsci é considerado um "comunista crítico", um "ponto de partida de uma original possibilidade de ser comunista depois da crise do 'socialismo real” (p. 17). A segunda leitura, pelo contrário, é relacionada a interpretações que entendem Gramsci como um autor liberal-democrata ou liberal-socialista. Ao considerá-lo liberal e libertário, enfatiza sua dimensão intelectual em detrimento àquela política.

De qualquer forma, se podemos afirmar que pensamento de Gramsci nas análises e estudos da esquerda brasileira ganhou terreno, muito é motivado pelo plano do método e dos conceitos básicos, como evidencia Coutinho (1993), ou seja, Gramsci além de nos proporcionar uma chave de leitura histórica, livre de qualquer forma de determinismo, nos presenteia com categorias, como hegemonia, revolução passiva, intelectuais, Estado ampliado, classes subalternas, etc., que contribuem para entendermos o movimento contraditório do capitalismo moderno e mesmo as particularidades do modo de produção periférico brasileiro.

O presente trabalho visa realizar uma análise acerca do desenvolvimento do Estado brasileiro até os dias atuais a partir das contribuições teóricas de Gramsci, principalmente as categorias de Estado ampliado, hegemonia, revolução passiva, guerra de posição e de movimento, transformismo e fascismo. 
Se divide fundamentalmente em dois pontos, no primeiro trazemos algumas aproximações sobre o conceito de Estado em Gramsci no qual recorremos diretamente as Edizione critica dell'Instituto Gramsci, de 2014, organizado por Valentino Gerratana, editora Einaudi. No segundo ponto do artigo discorremos sobre o desenvolvimento do Estado brasileiro à luz do pensamento do comunista italiano. Tal análise contou também com a contribuição de autores nacionais como Carlos Nelson Coutinho (1993) e Florestan Fernandes (2006).

\section{Aproximações ao conceito de Estado em Antonio Gramsci}

Ao se debruçar sobre o estudo histórico, econômico, social e político de um país da periferia europeia, Antonio Gramsci analisa o capitalismo na sua fase monopolista, do século XX. Seu olhar se volta para entender a experiência de revolução de 1917 - Revolução Russa, o papel do Estado, dos intelectuais, das classes dominantes e subalternas. Assim, mantendo a ortodoxia marxiana, Gramsci entende que o conceito de Estado deve incorporar novos elementos, deve se complexificar acompanhando o desenvolvimento do capitalismo monopolista e sua luta para (re)produção não apenas econômica, mas também cultural, ideológica e política.

O debate sobre a concepção de Estado está presente em diversos momentos de sua vasta obra. Gramsci (2014) compartilha da concepção marxiana sobre o Estado, ou seja, ele entende tal instituição como fruto do processo dialético e histórico de uma sociedade dividida entre duas classes sociais fundamentais. Particularmente nos escritos carcerários podemos destacar o Caderno 10 no qual ele afırma o "Estado como agente econômico enquanto mesmo sinônimo de tal situação" (CRAMSCI, 2014a, Q 10, p. 1310). O Estado é também considerado um dos dois planos da superestrutura, sendo o outro o plano da sociedade civil.

Contudo, para Gramsci como primeiro passo para se compreender seja o Estado em sua especificidade histórica, sejam as alternativas re- 
volucionárias mais adequadas a cada tipo de sociedade; está a diferenciação entre suas particularidades. Tal raciocínio é essencial dentro do pensamento gramsciano para entendimento das "estratégicas revolucionárias de Trotski e Lenin, à simbologia militar da 'guerra de posição' e da 'guerra manobrada'" (LICUORE; VOZA, 2009, p. 602). Estamos falando da distinção entre sociedades "orientais" e sociedades "ocidentais".

Tal diferenciação está longe de se seguir a mera separação geográfıca-territorial, ou mesmo de seguir um padrão "standardizzato", está assim associado ao desenvolvimento histórico de cada formação, às "condições gerais-econômicas-culturais-sociais de um país" (GRAMSCI, 2014b, Q 7, p. 865), particularmente do Estado e da organização da sociedade civil. Sobre tal argumento vale evidenciar as palavras do autor:

No Oriente o Estado era tudo, a sociedade civil era primitiva e gelatinosa; no Ocidente entre Estado e sociedade civil havia uma justa relação e quando se dava um abalo do Estado, percebia-se imediatamente uma robusta estrutura da sociedade civil. O Estado era apenas uma trincheira avançada, por trás da qual havia uma robusta cadeia de fortalezas e casamatas; mais ou menos, de Estado a Estado, se entende, mas precisamente isso exigia um rigoroso reconhecimento de caráter nacional (GRAMSCI, 2014b, Q 7, p.866).

Dada a sua organização e estrutura, nos países considerados "orientais" a "guerra de movimento" ou "guerra manobrada" seria a melhor alternativa para tomada do poder. Para Gramsci tal forma de guerra é "o reflexo das condições gerais-econômica-culturais-sociais de um país cujos quadros da vida nacional são embrionários e liderados e não podem transformar-se "trincheira ou fortaleza” (GRAMSCI, 2014b, Q 7, p.865).

Por outro lado, nos países considerados “ocidentais", o Estado assumi uma forma "ampliada" e a sociedade civil torna-se também articulada e forte. Nesse sentido, podemos fala de um processo de "ocidentalização" da sociedade que está ligado à socialização da política, 
que se expressa na organização e constituição no âmbito da sociedade civil de sindicatos, partidos, grupos políticos, etc.

Ao considerarmos o desenvolvimento do capitalismo monopolista e suas bases liberais, Coutinho (1993) afırma que a dinâmica da ocidentalização pode ser considerada um fenômeno universal. Para tais situações Gramsci evidencia como estratégia socialista não o confronto direto e espontâneo (a "guerra de movimento" aplicada com sucesso na Rússia), mas a "guerra de posição". Vale observar que o autor italiano faz referência as reflexões e contribuições de Lenin sobre tal argumento.

Assim, o autor considera que nas "sociedades ocidentais", os dois planos são dialeticamente unidos no conceito "Estado integral", tal conceito indica uma relação de "unidade-distinção" entre a sociedade civil e a sociedade política. Logo, “a guerra de movimento [...] é considerada por Gramsci, uma forma inadequada do conflito político moderno" (LICUORE; VOZA, 2009, p.379). Porém, pode ser utilizada quando se tratar de conquistar posições não decisivas e quando não for possivel mobilizar todos os recursos dos aparatos de hegemonia e do Estado, caso contrário, cabe a "guerra de posição", sob tal argumento discutiremos detalhadamente mais à frente.

O marxista italiano sinaliza ainda no Caderno 4 que "a distinção entre sociedade política e sociedade civil [...] é puramente metódica, não organiza e na concreta vida histórica a sociedade política e sociedade civil são uma mesma coisa" (GRAMSCI, 2014c, Q4, p.460), ou seja, "Sociedade civil é também ela o Estado, ou melhor é o Estado mesmo" (GRAMSCI, 2014a, Q 26, p. 2302). Em outras palavras: “na noção geral de Estado entram elementos que devem ser remetidos à noção de sociedade civil (no sentido, seria possível dizer, de que Estado= sociedade política+sociedade civil, isto é, hegemonia couraçada de coerção)." (CRAMSCI, 2014b, Q 6, p. 763-764).

Dessa forma, pensar em Estado para Gramsci é entendê-lo também no processo de construção do consenso, e/ou mesmo coerção, que possui como uma de suas funções estabelecer a hegemonia e repro- 
dução da subalternidade das classes sociais frente à classe dominante. Na luta pela construção da hegemonia, o Estado "educa ao consenso", no sentido de ser uma entidade que adéqua à sociedade civil à estrutura econômica (GRAMSCI, 2014b, Q 10, p.1253).

O Estado tem e pedi o consenso, mas também "educa" esse consenso com as associações políticas e sindicais, que, porém, são organismos privados, deixados a iniciativa privada da classe dirigente (GRAMSCI, 2014c, Q 1, p. 56).

Ao analisar o Estado no século XIX, Gramsci entende que esse assume um novo protagonismo em contextos políticos diversos, ou seja, tanto no campo econômico quanto na organização da sociedade para a criação do consenso. Daí a importância do Estado na construção de uma opinião pública (CRAMSCI, 2014b, Q 7, p. 914).

É também de grande importância a compreensão gramsciana de que para um grupo ascender ao poder não bastaria somente ser dominante, mas também ser dirigente, e para isso é necessário construir o consenso na sociedade, a fim de conquistar a hegemonia. Assim, na disputa pela direção é essencial a atuação de "intelectuais" que ligados à sua classe, atuem como funcionários na disseminação da ideologia da classe de sua origem ${ }^{5}$.

Nesse sentido, o Estado ampliado, em suas diferentes facetas (sociedade civil, intelectuais, aparelhos privados e ideológicos, etc.), visa à construção por um lado do consenso 'espontâneo', e por outro lado de um aparato que possa garantir uma coerção estatal que "assegura 'legalmente' a disciplina daqueles grupos que não 'concedem' nem ativamente nem passivamente, mas é constituído para toda a sociedade em previsão dos momentos de crise no comando e na direção cujo consenso espontâneo vem menos" (GRAMSCI, 2014a, Q 10, p. 1518-19).

Sendo então o Estado integral atravessado da luta hegemônica, a classe subalterna luta para manter a própria autonomia e às vezes para construir uma própria hegemonia, alternativa àquela dominante (LIGUORI, VOZA, 2011, p.804). 
Um outro "instrumento-chave" trabalhado pelo comunista sardo foi o conceito de "guerra de posição", ou seja, a disputa expressa no "assédio recíproco" entre as classes que se desenvolvem constantemente em todas as modernas sociedades capitalista (GRAMSCI, 2014a, Q 13, p. 1615). Tal "guerra" acontece anteriormente ao próprio confronto armado, pois para o capitalismo moderno é essencial não apenas para acumular material bélico, mas também recursos humanos, técnicos e sociais; no sentido de criar verdadeiras fortalezas ideológicas.

A guerra de posição possibilita nas palavras de Gramsci:

[...] a realização de um aparato hegemônico, enquanto se cria um novo terreno ideológico, determina uma reforma das consciências e dos métodos de consciência, é um fato de conhecimento, um fato filosófico (GRAMSCI, 2014b, Q 10, p. 1.250)

Conforme afirmamos acima, o marxista italiano entende que para os países de Estado moderno a "guerra de movimento" se apresenta imprópria, pois a estrutura de Estado e sociedade em tais realidades assume uma complexidade bem mais ampla, sendo mais adequada a "guerra de posição", contudo com tal afırmação Gramsci não subjuga a ideia de "movimento" na luta política, não nega importância da espontaneidade na ação dos grupos revolucionários.

Dessa forma, afirma Gramsci "que em cada movimento 'espontâneo' existe um elemento primitivo de direção consciente, de disciplina, isso é demonstrado indiretamente pelo fato de que existem correntes e grupos que defendem a espontaneidade como método" (GRAMSCI, 2014b, Q 8, p. 329). Contudo, ele coloca ainda da necessidade de que está "espontaneidade" seja "educada" e tornada homogênea à própria teoria moderna do Estado contemporâneo.

O seu raciocínio se concentra sob os fundamentos e os objetivos de tal movimento, que não pode ficar prisioneiro do "imediatismo", vale dizer daquilo que de arbitrário, de aventureiro, de artefato e de não historicamente necessário existe em cada movimento" (LICUORE; VOZA, 2009, p. 380). 
Ainda dentro do debate do Estado, outra grande contribuição foi o reconhecimento "revolução passiva" ou "revolução-restauração" como estratégia adotada pelo Estado moderno e classes dominantes para manutenção da ordem. Afirma Cramsci que quando as classes dominantes se veem diante do subversivismo esporádico e desorganizado das massas populares passam a adotar uma "restauração" da ordem incorporando também certa parte das exigências populares (GRAMSCI, 2014b, Q 8, p. 957). Tal processo está ligado à formação dos Estados modernos na Europa continental, particularmente ao Risorgimento italiano.

Embora estejamos falando da manutenção/restauração de um contexto econômico e político, Gramsci também evidencia que a revolução passiva pode vir somada a "modificações moleculares, que, na realidade, modificam progressivamente a composição anterior das forças e, por conseguinte, tornam-se matriz de novas modificações" (GRAMSCI, 2014a, Q 15, p. 1767).

A “revolução passiva”, juntamente com a "guerra de posição”, são estratégias adotadas pelo Estado e classes dominantes, para manutenção da hegemonia. "A guerra de posição é a forma essencial com que se dá a revolução passiva do liberalismo do século XIX e do fascismo do século XX" (LIGUORE; VOZA, 2009, p. 384).

Para Gramsci o fascismo, entendido como produto da história, da grande guerra e da cultura italiana; se expressa como uma nova forma de "revolução passiva" criada pelas classes dirigentes italianas para obstaculizar o risco de uma crise econômica e consequente precipitação do conflito social (GRAMSCI, 2014b, Q 8, p. 1089). É também expressão da "militarização do conflito de classes ocorrida desde 1917 em diante" (LIGUORI; VOZA, 2009, p.297). Podemos entendê-lo como uma contrarrevolução preventiva que objetiva retomar nos aspectos econômico, político, social, ideológico e cultural das classes dirigentes. 


\section{Gramsci e a realidade brasileira}

Ao seguirmos o "filo rosso" do pensamento de Gramsci sobre o Estado, entendemos que para um estudo mais particular do Estado brasileiro precisamos inicialmente entender os elementos de sua formação econômica, histórica, política e social. Assim, nesse ponto traremos além das contribuições de conceitos trabalhados pelo autor, abordaremos também autores brasileiros que buscaram entender a realidade do "mezzogiorno tropical" (BIANCHI, 2019).

A modernização do capitalismo brasileiro se deu sem a realização de uma "revolução burguesa", como aconteceu nos países do norte da Europa. O sociólogo brasileiro Florestan Fernandes (2006) considera que o capitalismo no Brasil assume um lugar de subalternidade em relação ao capital internacional. Ao invés de uma revolução progressista permeada pelo ideal nacional-democrático, no Brasil a burguesa preservou e incorporou os elementos da aristocracia autocrática e fez alianças com o capitalismo internacional imperialista.

Ao estudar o sistema escravagista nacional, Fernandes (2006) afirma que esse se inseriu no quadro do lucro, fortaleceu e constituiu uma elite senhorial e patrimonialista, um capitalismo marginal. Contudo, mas do que produzir desdobramentos econômicos e sociais, tal sistema produziu um complexo cultural de mentalidades e relações sociais elitista, senhorial, conservadora, oligárquica e provinciana.

Ao contrário de outras burguesias, que forjaram instituições próprias de poder especificamente social e só usaram o Estado para arranjos mais complicados e específicos, a nossa burguesia converge para o Estado e faz sua unificação no plano político [...]. Em consequência, a oligarquia não perdeu a base de poder que lograra antes, como e enquanto aristocracia agrária; e encontrou condições ideais para enfrentar a transição modernizando-se, onde isso fosse inevitável, e irradiando-se pelo desdobramento das oportunidades novas, onde isso fosse possível. (FERNANDES, 2006, p. 240). 
Logo, a burguesia brasileira não foi capaz de realizar uma "revolução democrático-burguesa", conforme o modelo jacobino, constituindo-se assim como uma burguesia conservadora, escravagista, antipopular e racista, que captura do Estado para realizar seus interesses. Mesmo com a instituição da república e da democracia no país, seu caráter conservador sempre tenderá a retornar na cena política. O sociólogo brasileiro utiliza a expressão "democracia restrita", ou seja, a democracia e os direitos civis no Brasil tenderão a existir somente para as elites e as classes dominantes.

Diante da ausência de uma revolução burguesa minimamente progressista, o movimento político das classes dominantes brasileiras será voltado a rearranjos no sentido de manter se cerne conservador, daí o conceito "drama crônico" (FERNANDES, 2006), ou seja: “como não há ruptura definitiva com o passado, a cada passo este se reapresenta na cena histórica e cobra o seu preço, embora sejam muito variáveis os artifícios da "conciliação" (FERNANDES, 2006, p. 238).

Vemos emergir um Estado nacional forte e "blindado" frente às reivindicações dos grupos subalternos, que assume a função de "dirigir" politicamente as classes econômicas dominantes. Ao deixar de lado as formas hegemônicas, o Estado privilegia as formas ditatoriais e a prática do transformismo como "modalidade de desenvolvimento histórico que implica a exclusão das massas populares" (COUTINHO, 1993, p.112). Para esses casos em que é privilegiado do "domínio" em detrimento da "direção", Gramsci fala de "ditaduras sem hegemonia", na qual "a hegemonia será de uma parte do grupo social sob inteiro grupo, não desse sobre outras forças a fim de potenciar o movimento, de radicalizá-lo etc., segundo o modelo “jacobino” (GRAMSCI, 2014c, $\mathrm{Q} 15, \mathrm{p} .1823-1824)$. Se entre as classes dominantes nacionais observa-se a disputa pela hegemonia, para com as classes subalternas, por outro lado, é delegado ao Estado o papel de "direção".

Todavia, como garantir a manutenção do status quo em situações de "ditadura sem hegemonia"? Mediante a cooptação/assimilação de 
frações rivais pelos grupos do poder, ou seja, pela adoção do "transformismo". Este pode se dar de duas formas: pela incorporação de personalidade políticas que originalmente pertenciam a grupos/partidos historicamente democráticos pelos grupos mais conservadores; e, pelo transformismo de grupos radicais inteiros que passam ao campo mais moderado/conservador.

É nesse contexto que podemos observar em diversos momentos de nossa trajetória histórica a adoção da "revolução passiva" e do "transformismo", como estratégia do Estado burguês de restaurar e manter a sua dominação diante as pressões populares (de "baixo para cima"). Tal prática possibilitou a incorporação de algumas demandas populares, por outro lado, a burguesia continua a aliar-se com os antigos grupos aristocráticos.

Para burguesia tupiniquim a "revolução passiva" sempre foi entendida como um imperativo. Coutinho (1993) cita como exemplo a Ditadura de Vargas em 1937, assim como também a Ditadura Militar de 1964 a 1985, que preparou e garantiu as bases econômicas (industrialização agrária e urbana) para possibilitar a expansão do capitalismo monopolista, em certa medida, conseguindo ainda um significativo consenso entre alguns setores das camadas médias (COUTINHO, 1993).

Uma questão de total importância para o estudo do pensamento de Gramsci no Brasil é a definição do tipo de sociedade, ou seja, se o nosso país pode ser caracterizado como "oriental" ou "ocidental" em termos gramscianos. Carlos Nelson Coutinho (1993) nos lembra que embora a "ditadura sem hegemonia" e a "revolução passiva" sejam características fundamentais da nossa forma, o que significa um Estado forte - especificidade das sociedades "orientais", a formação social brasileira no decorrer de sua trajetória foi se desenvolvendo e adquirindo traços de uma "ocidentalização", sendo esta "o resultado de um processo histórico”, afirma Coutinho (1993, p.117).

Embora tenhamos na história nacional traços de um Estado forte e uma sociedade civil "gelatinosa", conforme afirmamos acima a partir 
do pensamento de Fernandes (2006), não podemos também negar os diferentes processos de nossa trajetória histórica que foram moldando nossa formação, como a abolição da escravatura e o processo de industrialização, tudo isso contribuiu para que a estrutura social do país se tornasse mais complexa, e mais moderna, ainda que o "moderno" permaneça estritamente vinculado com o atraso "pré-capitalista, sobretudo no campo (COUTINHO, 1993, p. 122).

Não obstante a tendência à "ocidentalização" brasileira tenha sido freada com a repressão e controle durante a Ditadura Militar de 1964 e com ela a censura, Atos Institucionais (Als), tortura e violência; ainda assim não conseguiu obstaculizar novas iniciativas. Mais tarde, nas décadas de 1970 e 1980, com o processo de organização e lutas da sociedade civil brasileira na luta pela eleição direta para Presidência da República, na constituição de sindicatos de trabalhadores, como por exemplo, o Partido dos Trabalhadores (PT) no ABC paulista, o Movimento dos Trabalhadores Rurais Sem Terra (MST) de caráter nacional, a luta pela redemocratização do país, aponta para constituição das bases objetivas para uma sociedade civil autônoma, embora tais iniciativas possam sofrer represarias do Estado. Assim:

Pondo em prática uma política econômica fortemente modernizadora, a ditadura promoveu um espetacular desenvolvimento das forças produtivas: sob a égide de uma "revolução restauração", o Brasil ingressou na fase do capitalismo monopolista de Estado. E essa modernização, mesmo sendo "conservadora" na medida em que manteve e aprofundou a dependência ao imperialismo, as desigualdades regionais e a desigual distribuição de propriedade e renda -, consolidou de modo irreversível os pressupostos objetivos da "ocidentalização" da sociedade brasileira (COUTINHO, 1993, p.125).

Destarte, no caso brasileiro, país com peculiar formação seja pela sua história, cravada pelo colonialismo, escravização e subordinação ao capitalismo internacional, seja pela constituição de uma burguesia 
e Estado; sua sociedade civil inicia seus passos para uma autonomização marcada fortemente pelo mix histórico entre os efeitos da revolução passiva, do transformismo, do cesarismo/bonapatismo e das diversas contrarreformas iniciadas com o neoliberalismo dos anos 1990.

Atualmente podemos dizer que após o período de mais de uma década de Ditadura civil e militar temos no Brasil uma sociedade "ocidental" nos moldes chamado por Coutinho (2010) de "norte-americano" preponderantemente neoliberal.

[...] caracterizado [...] pela presença de uma sociedade civil forte, bastante desenvolvida e articulada, mas na qual a organização política e a representação dos interesses se dá, respectivamente, por meio de partidos frouxos, não programáticos, e de agrupamentos profissionais estritamente corporativos. (COUTINHO, 2010, p. 40).

O período neoliberal em nível mundial, somado à crise da experiência do socialismo real e cooptação dos movimentos sindicais, irá inaugurar a era das contrarreformas neoliberais, processo sinalizado por Coutinho (2010) como diferentemente da "revolução-restauração", permeados pelo conservadorismo, mas também incorporando alguns avanços dos "de baixo" em um verdadeiro "reformismo conservador".

O movimento das contrarreformas não apresenta avanços nem para construção de um projeto contrário ao projeto capitalista nem para classe trabalhadora, não incorpora ganhos, mas procura retirar as poucas conquistas incorporadas no período da revolução passiva. “Na época neoliberal, não há espaço para o aprofundamento dos direitos sociais, ainda que limitados, mas estamos diante da tentativa aberta [...] de eliminar tais direitos, de desconstruir e negar as reformas já conquistadas pelas classes subalternas" (COUTINHO, 2010, p.37).

O início dos anos 2000 para praticamente toda América Latina foi marcado pela vitória eleitoral de partidos historicamente da esquerda para presidência da república. Particularmente no Brasil (governos Lula/Dilma Rousseff) tal período foi marcado por políticas de valorização do salário mínimo e unificação/implementação de Programas 
de Transferência de Renda, contudo foram governos que mantinham medidas neoliberais. Coutinho (2010) denomina tal momento como "hegemonia da pequena política", pois não entende que nos governos do período neoliberal havia modificações substanciais relacionadas às reivindicações da classe trabalhadora. Para o referido autor o momento da contrarreforma neoliberal traz como "pano de fundo" elementos da "pequena política", ou seja, da "política do dia a dia, política parlamentar, do corredor, da intriga" (GRAMSCI, 2014a, Q 13, p. 1563).

No contexto de hegemonia neoliberal, em detrimento da luta por projetos e princípios de sociedade ${ }^{6}$, estão postos disputas partidárias, questões meramente parciais e quotidianas (GRAMSCI, 2014a, Q 13, p. 1564), disputas por cargos. Sinaliza ainda o marxista sardo que "é, portanto da grande política a tentativa de excluir da grande política do âmbito interno da vida estatal e reduzir tudo à pequena política" (GRAMSCI, 2014a, Q 13, p. 1564).

Em meado do segundo mandato, a presidenta Dilma Rousseff, em 2016, sofre um aparelhado e orquestrado impeachment impulsionado por um movimento de direita. Tal evento foi caracterizado por alguns estudiosos como expressão de um golpe de estado. Assume o cargo de presidente o vice Michel Temer.

É possível afirmar que tal evento pode ser entendido como uma reiteração do chamado "drama crônico" (FERNANDES, 2006), como mencionamos acima, trata-se de um círculo vicioso que se repete reatualizando e reafirmando traços da heteronomia e do conservadorismo da burguesia nacional que se materializam no Estado e na sociedade civil.

O governo que se deu posteriormente foi de desmantelamento das políticas sociais existentes e ataque frontal aos direitos sociais e trabalhistas, podemos destacar a aprovação da Lei 13.467 de 13 de julho de 2019, que altera a Consolidação das Leis do Trabalho. Se utilizando principalmente de medidas "pelo alto", como as Emendas Constitucionais (EC), o curto governo aprova a EC 95, que instituiu um novo 
regime fiscal, medida inaudita que determina limite para os gastos da União para as próximas duas décadas.

O "golpe de 2016" parece na realidade ter sido apenas uma primeira fase para aniquilação de um ciclo. Em tal contexto de reafirmação dos setores conservadores brasileiros, reverberou fortemente nas eleições de 2018, que foram marcadas por manobras políticas que envolveram o parlamento e o setor jurídico. Como resultado do segundo turno das eleições de 2018, vence para presidente da república a chapa Jair Bolsonaro e vice o general Hamilton Mourão. Além das eleições de 2018 expressarem o aumento de candidatos ligados às forças armadas, o presidente eleito é notoriamente conhecido por suas posturas ultraconservadoras, machistas, sexistas, homofóbicas e racistas.

É importante entendermos que o processo nacional não está dissociado de um movimento maior que se caracteriza pelo ressurgimento de grupos fascistas de extrema direitos em diferentes países e governos pelo mundo, que a partir de aproximações ao pensamento gramsciano, poderíamos entender como uma reação conservadora frente àcrise orgânica do capital internacional.

Vemos a associação do neoliberalismo a pautas ideo-políticas de extrema direita, vale destacar as vitórias de candidatos reacionários à presidência de países que ocupam uma posição estratégica mundialmente, como Donald Trump (2016 a 2019) para os Estados Unidos da América, Matteo Salvini em 2018 (vice-primeiro-ministro) para Itália e Jair Bolsonaro em 2019 no Brasil.

A partir de março de 2020 o contexto nacional e internacional se acirram cada vez mais com a explosão da pandemia provocada pela Covid-19. A crise estrutural do metabolismo antissocial do capital potencializa a desigualdade e o racismo tanto em escala mundial como no interior de cada país. Concordamos com Ricardo Antunes (2020) no uso do termo "capital pandêmico", destacando ainda o caráter discriminatório e brutal da sociabilidade capitalista, penalizando a população pobre, negra, precária, desempregada, imigrante e refugiada. 
No hodierno momento da pandemia notamos por um lado, a incapacidade técnica e política por parte do Governo Federal em seu enfrentamento, como menosprezo à doença e suas consequências para população, bem como negação explicita da vacina, tais medidas se expressam no cruel número de mais de 300 mil mortes (dados de 26 de março de 2021) 7.

Por outro lado, temos o acelerado aviltamento da classe trabalhadora, particularmente da população negra. Se as taxas de ocupação foram afetadas negativamente para toda a classe trabalhadora no Brasil $^{8}$, tais índices são mais graves no interior da população negra.

A crise econômica e do trabalho intensificada pela pandemia afetou principalmente as mulheres negras, basta observar os dados sobre no tocante ao trabalho doméstico que é constituído principalmente por mulheres (92,3\%), entre as quais $67,7 \%$ são negras. $O$ contingente de pessoas ocupadas no trabalho doméstico teve uma perda de 11,5\%, passando de 4.458 mil (dados de maio) para 3.946 (dados de julho de 2020) (SILVA; SILVA, 2020) ${ }^{9}$.

Estamos de acordo com Antunes (2020, p. 14) ao afirmar que no contexto da pandemia a classe trabalhadora se encontra sob "intenso fogo cruzado", pois fica entre uma situação de extrema pobreza e à contaminação pelo vírus, ambas as situações empurrando para a "mortalidade e a letalidade".

\section{Considerações finais}

Embora Gramsci seja um autor que no Serviço Social é correntemente citado a partir de suas diferentes categorias (Estado, hegemonia, intelectuais, etc.) nota-se a necessidade de um maior aprofundamento de suas categorias e pensamento. Muitas vezes ele é analisado a partir de seus diferentes intérpretes com pouco recurso à produção gramsciana.

Antonio Gramsci nos deixou uma variada e complexa obra sob a qual são realizados diversos estudos de caráter político, filológicos e históricos. Tal pensamento nos proporciona uma leitura histórica, que 
se contrapõe ao determinismo, etapismo e evolucionismo de tendências equivocadas do próprio marxismo.

Dessa forma, a partir do pensamento inovador do comunista sardo podemos encontrar uma chave para o estudo do movimento contraditório do capitalismo moderno e mesmo das particularidades do modo de produção periférico brasileiro, pois Gramsci em suas analises procura entender elementos diversos da formação econômica, histórica, política e social.

Defrontamo-nos com um contexto no qual os estados nacionais são capturados para responder aos interesses do capitalismo em crise, que não se demonstra mais compativel com reformas progressistas e com políticas sociais minimamente estruturadas, retomando em nível mundial posturas de caráter ultraconservador e fascista.

Ao resgatar o pensamento do comunista sardo para a realidade brasileira, vemos uma sociedade que foi a duras penas se "ocidentalizando", malgrado os violentos e constantes ataques de uma burguesia nacional conservadora, que não foi capaz de realizar uma reforma democrática, seguindo os preceitos jacobinos. Tal classe se utiliza vigorosamente do Estado para garantir seus interesses, adotando historicamente a "revolução passiva" e o "transformismo" para tal.

As reflexões sobre o momento atual está ainda em aberto, nosso único imperativo é o de realizar "um cuidadoso reconhecimento do terreno” (GRAMSCI, 2014b, Q 7, p.866), de nossas formações sociais. Logo, o "retorno" à Gramsci nos leva ao conhecimento de nossas bases sociais, históricas e econômicas.

\section{Referências}

ANTUNES, Ricardo. Coronavírus. O trabalho sob fogo cruzado. São Paulo: Boitempo, 2020.

BIANCHI, Alvaro. Estudar e ensinar Gramsci: uma aventura no Mezzogiorno tropical. In: BIANCHI, Alvaro; MUSSI, Daniela; ARECO, Sabrina (Org.). Antonio Gramsci: filologia e política. Porto Alegre: Zouk, 2019. 
BIANCHI, Alvaro. O Laboratório de Gramsci. Filosofia, História e Política. 2 ed. Porto Alegre: Zouk, 2018.

COUTINHO, Carlos Nelson. As categorias de Gramsci e a realidade brasileira. In: COUTINHO, Carlos Nelson; NOGUEIRA, Marco Aurélio (Org.). Gramsci e a América Latina. 2 ed. São Paulo: Paz e Terra, 1993.

COUTINHO, Carlos Nelson. A hegemonia da pequena política. In: OLIVEIRA, Francisco de, BRACA, Ruy; RIZEK, Cidele (Org.). Hegemonia às avessas: economia, política e cultura na era da servidão financeira. São Paulo: Boitempo, 2010.

FERNANDES, Florestan. A revolução burguesa no Brasil. Ensaio de interpretação sociológica. 5 ed. São Paulo: Ed. Clobo, 2006.

GRAMSCI, Antonio. Quaderni del Carcere. Volume primo, Quaderni 1-5. Torino: Einaudi editore, 2014c.

GRAMSCI, Antonio. Quaderni del carcere. Volume secondo, Quaderni 6-11. Torino: Einaudi editore, 2014b.

GRAMSCI, Antonio. Quaderni del carcere. Volume terzo, Quaderni 12-29. Torino: Einaudi editore, 2014a.

LIGUORI, Guido. Gramsci conteso: interpretazioni, dibattiti e polemiche 1922-2012. Roma: Editori Riuniti University press, 2012.

LIGUORI, Guido; VOZA, Pasquale (a cura di). Dizionario Gramsciano 19261937. Roma: Ed. Carocci, 2009.

MODONESI, Massimo. Revoluções Passivas na América Latina. In: BIANCHI, Alvaro; MUSSI, Daniela; ARECO, Sabrina (Org.). Antonio Gramsci: filologia e política. Porto Alegre: Zouk, 2019.

NETTO, José Paulo. Ditadura e Serviço Social: Uma análise do Serviço Social no Brasil pós-64. 6 ed. São Paulo: Cortez, 2002.

SILVA, Salyanna de Souza. "Chicago boys" e neoliberalismo latino americano: uma análise gramsciana. In: Encontro Internacional de Política Social e $14^{\circ}$ Encontro Nacional de Política Social. 2019. Vitória. Resumos...Vitória: http:// periodicos.ufes.br/EINPS/article/view/25788, 2019.

SILVA, Tatiana Dias Silva, SILVA, Sandro Pereira. Nota Técnica Trabalho. População Negra e Pandemia: notas sobre os primeiros resultados da PNAD COVID-19. IPEA. Novembro, 2020. Disponivel em: http://repositorio.ipea. gov.br/bitstream/11058/10303/1/NT_46_Diest_TrabalhoPopula\%C3\%A7\%C3\%A3oNegraePandemia.pdf. Acesso: 21 de fevereiro de 2021. 
SIMIONATTO, Ivete. Recepções e difusão das ideias de Gramsci no Brasil: tendências e perspectivas. In: BIANCHI, Alvaro; MUSSI, Daniela; ARECO, Sabrina (Org.). Antonio Gramsci: filologia e política. Porto Alegre: Zouk, 2019.

SIMIONATTO, Ivete. Gramsci: sua teoria, incidência no Brasil, influência no Serviço Social. São Paulo: Cortez/UFSC, 1995.

\section{Notas}

1 Professora Adjunta do Departamento de Serviço Social da Universidade Federal do Espírito Santo (UFES). Doutora em Serviço Social pela Università degli Studi Roma Tre (UniromaTre/Itália). Mestre em Serviço Social pela Universidade Federal de Pernambuco (UFPE). Bacharel em Serviço Social pela Universidade Estadual do Ceará (UECE). ORCID nº 0000-0002-3329-4856. E-mail: salyannass@gmail.com

2 A partir de uma leitura etapista e isenta de contradições, o Brasil era analisado à luz do desenvolvimento capitalista europeu, logo "atrasado" e "semifeudal"; e a proposta de revolução copiava aquela realizada na Revolução Russa de 1917.

3 O Movimento de reconceptualização (ou reconceituação) do Serviço Social Latino-americano surge como expressão de crítica e renovação da profissão. Mesmo com curta duração (apenas uma década - 1965 a 1975), por causa de motivos externos (repressão das ditaduras presentes em praticamente todos os países do Cone Sul) e internos (heterogeneidade de posições e projetos entre seus participantes); a reconceptualização deixou como legado para o Serviço Social latino-americano uma aproximação à tradição marxista mais do que as demais experiências profissionais do continente (NETTO, 2002).

4 Palmiro Togliatti foi um importante representante do Partico Comunista Italiano (PCI). Além de secretario geral e representante do partido junto ao Partido Comunista Russo, Togliatti exerce também um papel central para a esquerda comunista italiana durante as eleições políticas e o processo de promulgação da Constituição de 1948.

5 O tema dos intelectuais e sua relação com as classes sociais sempre foi considerado fundamental para Gramsci. Em uma carta a Tatiana Schucht (sua cunhada), datada de 19 de março de 1927, o marxista italiano afirmou que era "atormentado" da ideia de que necessitaria fazer alguma coisa "für ewig" (do Alemão "para sempre", "para eternidade"). Assim, ele elabora um esboço dos cadernos subdividindo em quatro pontos: 1) reflexões sobre a função dos intelectuais italianos no desenvolvimento da questão meridional; 2) um projeto de estudos sobre a linguística comparada; 3) um estudo sobre o teatro de Pirandello e 4) um estudo sobre folhetins/romances e o gosto popular na literatura. Esses após a sua morte 
foram confiados a sua cunhada. Em 1947 a Editora Einaudi os publica pela primeira vez com o título "Cadernos do Cárcere".

6 Gramsci no (5). Grande política (alta política) - pequena política (política do dia a dia, política parlamentar, do corredor, da intriga) do Caderno 13, sinaliza para diferença entre as duas políticas. Para ele a grande política compreende às questões conectadas às formações de novos estados, com a luta para destruição, a defesa, a conservação de determinadas estruturas orgânicas econômico-sociais" (GRAMSCI, 2014a, Q 13, p. 1564).

7 Dados: https://covid.saude.gov.br/. Acesso em 26 mar. 2021.

8 Ao analisar dados da PNAD Covid-19, Tatiana Dias Silva e Sandro Pereira Silva (2020) evidenciam que dados do final do mês de maio de 2020 já apontavam para a redução em torno 7 milhões de pessoas em comparação ao mesmo período do ano anterior.

9 Dados da PNAD Covid-19 demonstram ainda que até mesmo o trabalho remoto, que foi adotado por muitas empresas durante a pandemia como medida de evitar a disseminação do vírus, foi mais adotado entre a população trabalhadora branca $(17,6 \%)$, que entre aquela negra (apenas 9\%). "Somente cerca de um terço do total de trabalhadores ocupados em atividade remota era composta de trabalhadores negros" (SILVA, SILVA, 2020, p.11). 


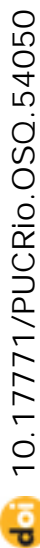

